\title{
Efficacy of Electrogalvanic Stimulation in Treatment of Levator Ani Syndrome Revisited
}

\author{
Mantilla $\mathrm{N}^{1}$, Paris $\mathrm{B}^{2}$, Abcarian $\mathrm{H}^{3}$, Cintron $\mathrm{J}^{3}$, Zavala $\mathrm{A}^{4}$, and Singer $\mathbf{M}^{5}$ \\ ${ }^{1}$ General Surgery Department, University of Illinois at Chicago, 840 S Wood St. Suite 518, Chicago, IL 60612, USA \\ ${ }^{2}$ Department of Colon \& Rectal Surgery, Springfield Clinic 1025 South 6th Street, Springfield, IL 62703, USA \\ 3John H. Stroger Hospital of Cook County, Colon \& Rectal Surgery 1900 West Polk St., Suite 402, Chicago, IL 60612, USA \\ ${ }^{4}$ Section of General Surgery, University of Chicago 5857 S Maryland Ave. DCAM 6A, Chicago, IL 60637, USA \\ ${ }^{5}$ Department of Colon \& Rectal Surgery, Highland Park Hospital 777 Park Avenue West, Highland Park, IL 60035, USA
}

\begin{abstract}
Introduction: Electrogalvanic stimulation (EGS) has been established as a safe and effective treatment for the management of levator ani syndrome (LAS). There is a paucity of recent literature regarding this treatment modality. The purpose of this study is to review recent experience with EGS in the treatment of levator ani syndrome at a single center.

Methods: A retrospective review of 22 patients treated with EGS for LAS from 07/04 to 08/08 was done. The EGS protocol begins with 30 minute sessions. Voltage is adjusted based on patient tolerance (range 100-330 volts) and is delivered at a frequency of 100 pulses per sec (pps). Length of treatment is gradually increased with increasing patient tolerance, from 30 to $60 \mathrm{~min}$. Each session starts with minimal voltage and is slowly increased to maximum tolerance, held for 15-20 minutes, then intensity is gradually reduced from the peak of $100-330$ volts to a minimum of $10-100$ volts. Most patients were treated three times weekly for two weeks (average, six treatments per patients). The mean number of sessions was 7.5 (range 2-15). The average of duration of each session was 29 minutes for the initial visit and 46 minutes for the concluding visit. The intensity was $70 \%$ at initial visit, and $88 \%$ by the last treatment (330 volts=100\%).
\end{abstract}

Results: Twenty two patients were treated $(72 \%$ males). The mean age was 56 years. The mean duration of symptoms was 60 months (range 3-240). 41 percent of patients had additional anorectal pathology. Over $60 \%$ of patients were taking muscle relaxants and/or analgesics. In this cohort, $59 \%$ of patients had previous treatment, including biofeedback (32\%), botox injection (14\%) and epidural injection (14\%). Patient assessment of results at the last treatment session: complete relief or significant improvement in 8 patients $(36 \%)$; moderate improvement in $2(9 \%)$; slight improvement in 7 (32\%); and no improvement or worsening of pain in 5 patients $(23 \%)$. The mean follow up was 11 months (range 0.4-38). There were no complications associated with the EGS. Both multiple linear regression and logistic regression showed the same results. The outcome of patients with levator ani syndrome treated with EGS is related to the number of treatment sessions and history of previous treatments (of any sort).

Conclusions: EGS is an effective treatment option in a selected group of patients with LAS. It offers significant to moderate improvement in $45 \%$ of patients with essentially no risk. Due to its safety profile and moderate efficacy, it should continue to be considered as a treatment operation for levator ani syndrome.

Keywords: Anismus; Electrogalvanic stimulation; Muscle spasm

\section{Background}

The Levator ani syndrome, also known as anismus, levator spasm, puborectalis syndrome, chronic proctalgia, pyriformis syndrome and pelvic tension myalgia [1,2], produces chronic anal pain which is often debilitating and characteristically referred to as constant and/ or frequent dull anorectal pain. Tenderness to palpation of the levator ani can be elicited in all patients. The pathophysiology of levator ani syndrome is poorly understood but the pain is a direct result of levator ani muscle spasm without an underlying organic disease.

There are no controlled studies of treatments for chronic intractable anorectal pain. However, some uncontrolled studies have reported very acceptable overall success rates with electrogalvanic stimulation [3-7], biofeedback training [3,8,9] digital massage of the levator ani muscles $[10,11]$, and sitz baths [12].

\section{Objectives}

We review our experience using EGS in the treatment of levator ani syndrome.

\section{Methods}

A retrospective chart review was conducted in 25 patients treated with EGS for levator ani syndrome from July 2004 to August 2008. All patients who underwent EGS in a single center were included for review. The study was done under an Institutional Review Board approval.

Patients' clinical histories were taken to ensure they did not have a pacemaker, as this is a contraindication for EGS. Patients were then educated about the procedure and placed in the left lateral decubitus position. Digital rectal examination was performed prior to each session to assess the point of worst tenderness. The dispersive pad was placed under the patient's left thigh and an intra-anal probe was inserted. Both

*Corresponding author: Herand Abcarian, MD, Colon and Rectal Surgery Department. John Stroger Hospital at Cook County, 1900 West Polk St., Suite 402, Chicago, IL, 60612, USA, Tel: 312-996-2061; Fax: 312-996-1214; E-mail: abcarian@uic.edu

Received April 21, 2014 ; Accepted April 28, 2014; Published May 15, 2014

Citation: Mantilla N, Paris B, Abcarian H, Cintron J, Zavala A, et al. Efficacy of Electrogalvanic Stimulation in Treatment of Levator Ani Syndrome Revisited. Journal of Surgery [Jurnalul de chirurgie] 2014; 10(2): 167-170 DOI: 10.7438/1584-9341-10-2-12

Copyright: $\odot 2014$ Mantilla N, et al. This is an open-access article distributed under the terms of the Creative Commons Attribution License, which permits unrestricted use, distribution, and reproduction in any medium, provided the original author and source are credited. 
were connected to the EGXtra ${ }^{\circ}$ Model EGS4000 (Cen-Med Enterprise Inc., East Brunswick, NJ) (Figure 1). The pulse per second dial was turned up to 100 . Voltage was adjusted based on patient tolerance but ranged from 100-330 volts and was delivered at a frequency of 100 pulses per sec (pps). The treatments began with 30 minute sessions. The length of sessions was gradually increased from 30 to $45 \mathrm{~min}$. Each session started with minimum voltage (generally around 150 volts), and slowly increased to the patient's maximum tolerance. During the increments of voltage, patients were asked about their tolerance, so they that the voltage could be appropriately adjusted. The intensity was kept at this level for half of the session and, then gradually decreased from 100-330 volts to $10-100$ volts. Lastly, the dispersive pad site is checked for any signs of burns. Multiple linear regression and logistical regression analysis was performed using NORM software.

\section{Results}

A total of 22 patients were treated. The majority were males (72\%). The mean age was 56 years old (range 30-86). The mean duration of symptoms was 60 months (range 3-240). 41 percent of patients had additional anorectal pathology (anal fissure, anal fistula and hemorrhoids). Over $60 \%$ of patients were taking muscle relaxants and/ or analgesics. Fifty-nine percent of patients had previous treatments, including biofeedback (32\%), botox injection (14\%) and epidural injection (14\%). The mean number of EGS sessions was 7.5 (range $2-15$ ). The average duration of each session was 29 minutes for the initial visit and 46 minutes for the concluding visit. The intensity was $70 \%$ at initial visit, and $88 \%$ by the last treatment ( 330 volts $=100 \%$ ). Patients' assessment of results at the last session is shown in Figure 2. Complete relief or significant improvement in $8(36 \%)$; moderate improvement in 2 (9\%); slight improvement in 7 (32\%); and no improvement or worsening of pain in 5 (23\%). The mean follow up was 11 months (range 0.4-38). There were no complications associated with the EGS. Table 1 summarizes our patient population based on gender, time with the diagnosis (months), previous treatments before undergoing EGS, number of EGS sessions and the outcomes after the last session. In the "Results" column we assessed the outcomes according to the Visual Analog Scale for pain reported by the patients in the chart during the

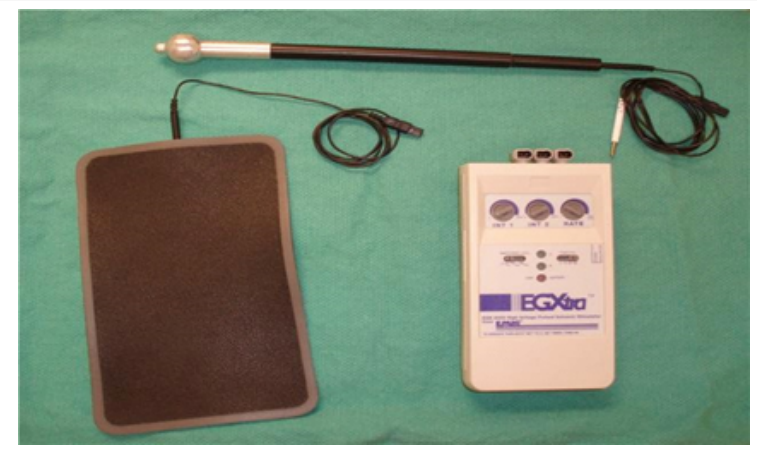

Figure 1: EGXtra Model EGS4000.

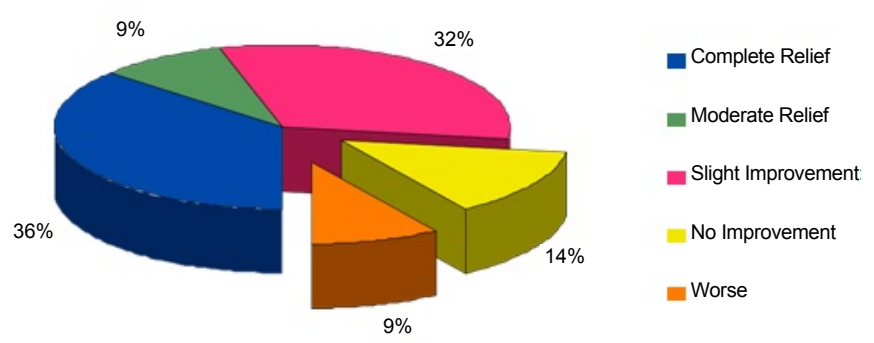

Figure 2: Distribution of patients' assessments of outcomes at the last EGS session.
Table 1: Distribution of patients' population by gender, time with the diagnosis, number of EGS sessions, previous treatments and final results.

\begin{tabular}{|c|c|c|c|c|c|}
\hline Patient & Gender & $\begin{array}{l}\text { Time with the } \\
\text { Diagnosis } \\
\text { (months) }\end{array}$ & $\begin{array}{l}\text { Number of } \\
\text { sessions }\end{array}$ & $\begin{array}{l}\text { Previous } \\
\text { Treatments }\end{array}$ & Results \\
\hline 1 & $\mathrm{~F}$ & 15 & 10 & 1 Botox injection & $8-->9$ \\
\hline 2 & M & 8 & 15 & & $7-->2$ \\
\hline 3 & M & 20 & 6 & Biofeedback & $8-->4$ \\
\hline 4 & M & 5 & 10 & $\begin{array}{l}\text { Biofeedback } \\
2 \text { Botox injections }\end{array}$ & 8-9 --> 7-8 \\
\hline 5 & M & 1 & 5 & Biofeedback & $10-->8$ \\
\hline 6 & $\mathrm{~F}$ & 0.5 & 2 & & $5-->10$ \\
\hline 7 & $\mathrm{~F}$ & 0.42 & 6 & & $8-->0$ \\
\hline 8 & M & $1.5-2$ & 6 & & Increased \\
\hline 9 & M & $0.33-0.42$ & 3 & & Increased \\
\hline 10 & M & 0.33 & 12 & & $5-->3$ \\
\hline 11 & $M$ & 3 & 15 & Biofeedback & $7-->3$ \\
\hline 12 & M & 2.5 & 7 & Biofeedback & Decreased \\
\hline 13 & M & 0.67 & 6 & & $5.5->0$ \\
\hline 14 & $\mathrm{~F}$ & & 6 & Epidural injection & $9-->10$ \\
\hline 15 & M & 10 & 6 & & $6-->3$ \\
\hline 16 & M & 13 & 4 & 2 Epidural injections & $7-->5-6$ \\
\hline 17 & $\mathrm{~F}$ & 2 & 12 & $\begin{array}{l}2 \text { Epidural injections } \\
\text { Biofeedback }\end{array}$ & $10-->7$ \\
\hline 18 & $\mathrm{~F}$ & 1.16 & 6 & & $9-10-->1-2$ \\
\hline 19 & M & 1.5 & 9 & $\begin{array}{l}\text { Biofeedback } \\
1 \text { Botox injection }\end{array}$ & $9-->6-7$ \\
\hline 20 & M & 0.42 & 6 & & $6-7-->0$ \\
\hline 21 & M & 7 & 6 & & $10-->4$ \\
\hline 22 & $M$ & 4 & 6 & & $6-7-->0$ \\
\hline
\end{tabular}

Source: Medical Records. University of Illinois at Chicago Medical Center.

initial and final sessions. Empty cells meant that the information was not available in the patient's chart, and results for patients 08,09 and 12 were not reported using the Visual Analog Scale, therefore data was reported the same way it was collected in the medical needs.

Both Multiple Linear Regression and Logistic Regression show the same results that The EGS treatment results were influenced by the number of sessions and the previous treatment prior the EGS. In addition, a greater number of sessions can help the EGS treatment to decrease the pain score remarkably; however, the more previous treatment affect the results adversely. Both of the two approaches indicate that a patient is more likely to be treated successfully by the EGS treatment with a greater number of sessions. But a patient is not more likely to be treated successfully by the EGS after other prior treatments.

Scatter plots were used to indicate whether there are linear relationship between the continuous predictor variables and the outcome variable. Figure 3 shows that there is a linear relationship between number of sessions and treatment success. However, there is no clear cut linear relationship between the time withthe diagnosis and treatment success.

\section{Discussion}

Early in the 1980's, high voltage electrogalvanic stimulation for the treatment of the levator ani syndrome started to be utilized. In 1982, Sohn et al published a series of 80 patients treated successfully with EGS, with total relief of pain in $69 \%$ of the patients [6].

Nicosia and Abcarian in 1985 showed that electrogalvanic stimulation provided total relief of pain symptoms in eighty percent of a cohort of 45 patients with only two patients reporting no benefit [13]. 


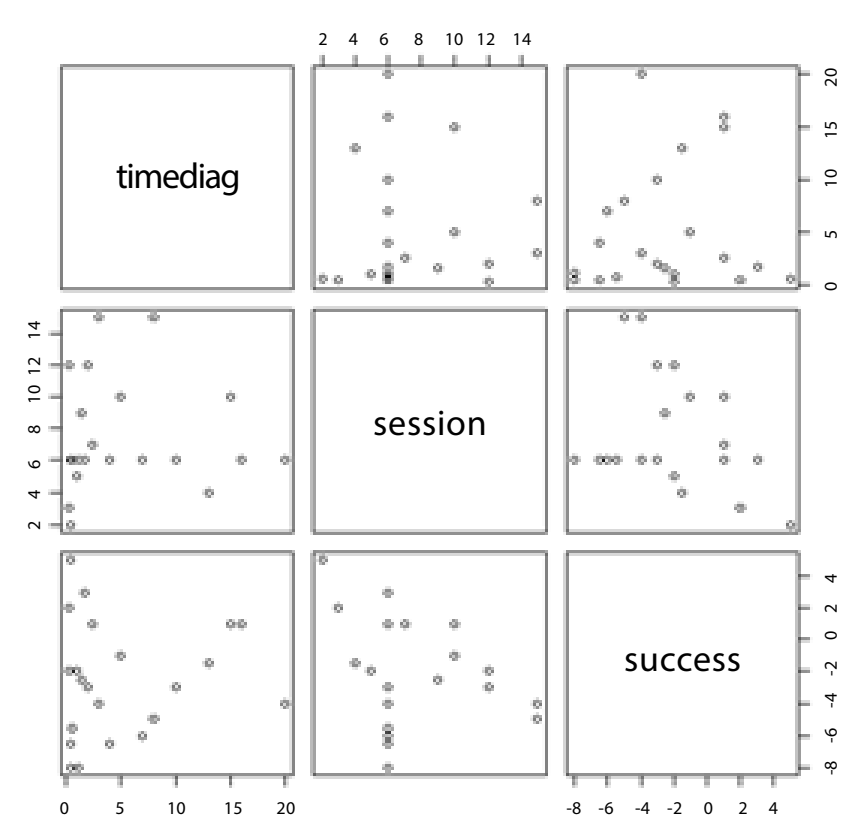

Figure 3: Scatter plots showing the relationship between number of sessions and success with treatment with EGS.

Also in 1985, Oliver et al. stated that of those correctly diagnosed with levator ani syndrome, seventy-seven percent experienced symptomatic relief with EGS [14]. Most articles stress that the diagnosis of levator ani syndrome requires that organic causes of anorectal pain be excluded [15]. In 1987, a study of twenty-eight patients showed success of $50 \%$ after eight treatments. The authors noted that patients with irritable bowel syndrome (IBS) or previous anorectal surgery were least likely to benefit from EGS [16].

Drossman et al. reported that the prevalence of symptoms compatible with levator ani syndrome in the general population was $6.6 \%$ and that more than $50 \%$ of this of patients were $30-60$ years old. Women were noticeably more affected than men (7.4\% vs. $5.7 \%)$ [2]. However, these results were contrary to our patient population where men predominated $(72.3 \%)$.

Diagnosis of levator ani syndrome is one of exclusion and many patients are refractory to treatment. Patients describe the pain as a vague, dull ache, fullness pressure sensation high in the rectum that often gets worse with sitting. On physical examination, overly spastic levator ani muscles can be felt; tenderness to palpation of pelvic floor muscles represents a cardinal symptom and prominent finding. For unknown reasons, the tenderness is frequently asymmetric, affecting mostly the left side [3]. The pathophysiology remains unknown. Patients with levator ani syndrome are often troubled with psychological co-morbidities associated with chronic anal pain which may result in social isolation. In a study by Ger et al., one fourth of patients had coexisting psychiatric conditions most commonly anxiety and depression [3]. It is uncertain if the association between chronic pelvic pain and psychosocial distress in multiple domains represents an underlying cause or a consequence of pain [1-5]. Electro-physiologic testing suggests increased anal pressures which may reflect increased external and/or internal anal sphincter tone [1]. Noninvasive treatment options for levator ani syndrome include sitz baths, biofeedback, analgesics and muscle relaxants while more invasive options include digital message, botox injection, steroid and epidural injections, and electrogalvanic stimulation (EGS) [17].

Hull and colleagues in 1993 reported forty-three percent of patients had at least partial relief of symptoms with a mean follow-up of more than two years [18].
Most treatments provide temporary relief and often require multiple visits [19]. Billingham et al. confirmed this in a study of twenty patients with levator ani syndrome treated with EGS. Sixty percent of their patients had immediate pain relief, one-third of which eventually had recurrent pain [20]. Few recent trials have looked at the efficacy of EGS in the treatment of levator ani syndrome. We hypothesize that EGS is still a viable adjunct in the management of this troubling disorder and an effective treatment for levator ani syndrome. In 2003 women with pelvic pain from levator spasm were treated with vaginal EGS by gynecologists and more than half of them had long-lasting relief of 6 months or more [21]. Our data support results similar to the above mentioned studies, with $45 \%$ of patients showing benefit from EGS.

\section{Conclusion}

Electrogalvanic stimulation for the treatment of LAS seems to have similar success rate for more than three decades. The vast majority of publications have reported the utility and superiority of EGS to other therapeutic modalities. Therefore, it is safe to conclude that EGS is an effective treatment option in a selected group of patients with levator ani syndrome offering moderate or complete symptomatic relief in $45 \%$ of patients with essentially no risk. Analysis of our data confirms that the more EGS sessions performed yields more successful symptom relief based on visual analog pain scales. The results also showed that patients who had other treatments prior to EGS benefited less from it. Due to the safety profile and moderate efficacy, EGS should be considered as a treatment option for levator ani syndrome.

\section{Conflict of interest}

The authors have no conflict of interest to report.

\section{References}

1. Bharucha AE, Trabuco E (2008) Functional and chronic anorectal and pelvic pain disorders. Gastroenterol Clin North Am 37: 685-696.

2. Drossman DA, Li Z, Andruzzi E, Temple RD, Talley NJ, et al. (1993) U.S householder survey of functional gastrointestinal disorders. Prevalence, sociodemography, and health impact. Dig Dis Sci 38: 1569-1580.

3. Ger GC, Wexner SD, Jorge JM, Lee E, Amaranath LA, et al. (1993) Evaluation and treatment of chronic intractable rectal pain--a frustrating endeavor. Dis Colon Rectum 36: 139-145.

4. Grant SR, Salvati EP, Rubin RJ (1975) Levator syndrome: an analysis of 316 cases. Dis Colon Rectum 18: 161-163.

5. Anderson RU, Orenberg EK, Chan CA, Morey A, Flores V (2008) Psychometric profiles and hypothalamic-pituitary-adrenal axis function in men with chronic prostatitis/chronic pelvic pain syndrome. J Urol 179: 956-960.

6. Sohn N, Weinstein MA, Robbins RD (1982) The levator syndrome and its treatment with high-voltage electrogalvanic stimulation. Am J Surg 144: 580-582.

7. Ware, JE, Jr. SF-36 health survey: Manual and interpretation guide. Boston The Health Institute, New Englad Medical Center; 1993. 40:187-189.

8. Grimaud JC, Bouvier M, Naudy B, Guien C, Salducci J (1991) Manometric and radiologic investigations and biofeedback treatment of chronic idiopathic anal pain. Dis Colon Rectum 34: 690-695.

9. Gilliland R, Heymen JS, Altomare DF, Vickers D, Wexner SD (1997) Biofeedback for intractable rectal pain: outcome and predictors of success. Dis Colon Rectum 40: 190-196.

10. Heah SM, Ho YH, Tan M, Leong AF (1997) Biofeedback is effective treatment for levator ani syndrome. Dis Colon Rectum 40: 187-189.

11. Oyama IA, Rejba A, Lukban JC, Fletcher E, Kellogg-Spadt S, et al. (2004) Modified Thiele massage as therapeutic intervention for female patients with interstitial cystitis and high-tone pelvic floor dysfunction. Urology 64: 862-865.

12. Dodi G, Bogoni F, Infantino A, Pianon P, Mortellaro LM, et al. (1986) Hot or cold in anal pain? A study of the changes in internal anal sphincter pressure profiles. Dis Colon Rectum 29: 248-251.

13. Nicosia JF, Abcarian H (1985) Levator syndrome. A treatment that works. Dis Colon Rectum 28: 406-408.

14. Oliver GC, Rubin RJ, Salvati EP, Eisenstat TE (1985) Electrogalvanic stimulation in the treatment of levator syndrome. Dis Colon Rectum 28: 662-663. 
15. Ng CL (2007) Levator ani syndrome - a case study and literature review. Aust Fam Physician 36: 449-452.

16. Morris L, Newton RA (1987) Use of high voltage pulsed galvanic stimulation for patients with levator ani syndrome. Phys Ther 67: 1522-1525. Erratum in: Phys Ther 1988 Feb; 68(2): 265.

17. Park DH, Yoon SG, Kim KU, Hwang DY, Kim HS, et al. (2005) Comparison study between electrogalvanic stimulation and local injection therapy in levator ani syndrome. Int J Colorectal Dis 20: 272-276.

18. Hull TL, Milsom JW, Church J, Oakley J, Lavery I, et al. (1993) Electrogalvanic stimulation for levator syndrome: how effective is it in the long-term? Dis Colon Rectum 36: 731-733.

19. Kang YS, Jeong SY, Cho HJ, Kim DS, Lee DH, et al. (2000) Transanally injected triamcinolone acetonide in levator syndrome. Dis Colon Rectum 43: 1288-1291.

20. Billingham RP, Isler JT, Friend WG, Hostetler J (1987) Treatment of levator syndrome using high-voltage electrogalvanic stimulation. Dis Colon Rectum 30: $584-587$.

21. Fitzwater JB, Kuehl TJ, Schrier JJ (2003) Electrical stimulation in the treatment of pelvic pain due to levator ani spasm J Reprod Med 48: 573-577. 